\section{Abordagem geo-histórica sobre as primeiras ocupações litorâneas de Fortaleza-CE}

Resumo: Este artigo trata das relações entre a formação espacial do litoral de Fortaleza-CE e a formação dos primeiros fortes, que nortearão sua ocupação. Buscou-se com o estudo das imagens cartográficas, cotejando e confrontando com os registros fotográficos, além de outras fontes documentais, a fim de compreender como se deu o processo de ocupação da zona costeira fortalezense. Para tanto, realizou-se levantamento dos principais registros iconográficos dos Fortes construídos/idealizados em Fortaleza entre os séculos XVII e XVIII. A importância desse resgate geohistórico se justifica então pela importância de compreendermos o início das relações ali engendradas, e o norteamento dado a produção espacial que viria a tomar à atual capital cearense.

\section{Geo-historical approach on the first occupations of coastal in Fortaleza-CE}

\footnotetext{
Abstract: These paper deals with the relationship between the spatial formation of the coast of Fortaleza$\mathrm{CE}$ and the formation of the firsts strongs, which will drive its occupation. Sought with the study of cartographic images, comparing and contrasting with photographic records, and other documentary sources, in order to understand how was the process of occupation of the coastal zone fortalezense. Therefore, we surveyed the major iconographic Forts built / idealized in Fortaleza between the seventeenth and eighteenth centuries. The importance of this rescue geo-historical then justified by the importance of understanding the origins of the relations engendered, and guid given spatial production that would take the current capital of Ceará.
}

Tiago Estevam Gonçalves*

Fábio de Oliveira Matos**

* Professor do Instituto Federal de Educação, Ciência e Tecnologia do Ceará (IFCE). Bolsista de Produtividade do Programa de Apoio à Produtividade em Pesquisa do IFCE

** Doutorando no Programa de Pós-graduação em Geografia da Universidade Federal do Ceará (UFCE)

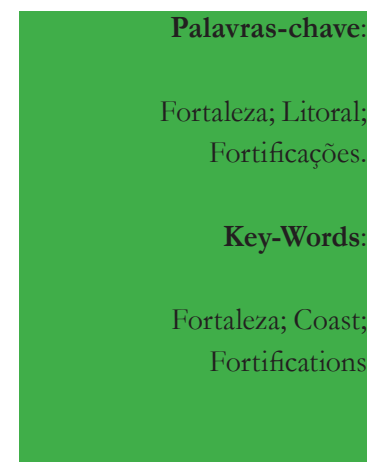

Geografia Ensino \& Pesquisa, vol. 17, n. 3, set./ dez. 2013. 


\section{Introdução}

$\mathrm{Na}$ busca por um campo da ciência geográfica que satisfizesse o interesse em estudar a geografia do passado do litoral de Fortaleza, optamos pela escolha da vertente de estudos realizados pela Geografia-Histórica. O contato inicial como essa linha se deu na descoberta dos anais do VIII Colóquio Internacional de Geocrítica, ocorrido em 2006 na Cidade do México, sobre o tema: Las ideas y los desafios de una organización en torno a la Geografia Histórica y la Historia del Territorio. Tratando sobre as bases e rumos dessa linha de pesquisa, é possível notar o quão rico a associativa entre a geografia e história pode resultar em reflexões sobre a formação espacial.

No âmbito desse debate, percebemos que pesquisas sobre a Geografia de Fortaleza são comuns, mas geralmente se restringem a um retrato da atualidade, sem haver o interesse de reaver os processos históricos de formação do espaço a ser pesquisado. É interessante observar que o inverso não ocorre da mesma forma, pois com a proposta de História-Geográfica, realizado no âmbito da História, há uma atenção voltada com os processos subsequentes de determinados fatos históricos para a espacialidade da cidade. Dessa forma, a construção da proposta de uma Geografia-Histórica de Fortaleza é um esforço no qual grande de nós, geógrafos, somos mais espectadores do que colaboradores.

Essa constatação em si possui algumas exceções. Existem diversas pesquisas sobre a história de Fortaleza, que são geográficas em sua essência, embora não tenham sido realizadas por geógrafos não diminuem a sua importância. No entanto, deve-se levar em consideração que os subsídios geográficos contidos nesses trabalhos são tratados como uma complementação àqueles oriundos da formação original do pesquisador. Giovanini (2006, p. 18) afirma que:

Ao contrário da História Geográfica e da Economia Social, que por não se prenderem às fronteiras de suas disciplinas, fornecem contribuições excepcionais ao mundo cientifico, não ocorre, com a mesma frequência, esse caminho inverso: geógrafos que, a partir de sua formação, façam incursões em outras ciências com o intuito de contribuírem para o desenvolvimento de um determinado tema.

Nesse sentido, propomos uma visão do percurso da ocupação litorânea em Fortaleza, tendo como base norteadora a formação dos primeiros fortes. Nesse interim, o presente trabalho remonta à tomada dos primeiros embates nessa espacialidade, momento em que o território onde seria construída a cidade de Fortaleza permanecia sob o domínio indígena.

\section{A Geografia-Histórica no entendimento de Fortaleza}

É importante observarmos que a Geografia-Histórica se ocupa em questões centrais da Geografia. Ela está intimamente ligada com as transformações geográficas através do tempo e os fatores que os produzem. Portanto há que percebermos que a suposta dualidade entre temporário e permanente que frequentemente passeia pela leitura em Geografia necessita de atenção. Capel (2006, p.02) ao falar do efêmero e do permanente em Geografia, nos lembra de que "tudo o que é aparentemente estável e duradouro acaba por resultar em algo fugaz e efêmero, dependendo da escala temporal que utilizamos".

Tudo se encontra em movimento e em constante mudança, mesmo que não seja visível ao nosso olhar. "Sucede em todo o universo, e também na natureza terrestre, onde os sistemas montanhosos estão sem dúvida modificando-se e onde a vida está igualmente em perpétuo movimento" (CAPEL, 2006, p. 02). Isto se apresenta de modo mais claro nos sistemas sociais, onde podemos observar mudanças mais claras em poucas décadas. O passado é constantemente abordado como "um país estranho" (LOWENTHAL, 1998, p. 63). De forma absoluta, ele não nos é alcançável; não se pode captar como um todo à nossa disposição nem se pode conhecer

Geografia Ensino \& Pesquisa, v. 17, n. 3 p. $54-63$, set./dez. 2013

Gonçalves, T.E.; Matos, F.O.

ISSN 2236-4994 55 
de forma segura, embora parcelar. Lowenthal (1998, p103) lembra que longe de simplesmente prender-se a experiências anteriores, o passado nos ajuda a entendê-las: "memórias não são reflexões prontas do passado, mas reconstruções ecléticas, seletivas, baseadas em ações e percepções posteriores e em códigos que são constantemente alterados, através dos quais delineamos, simbolizamos e classificamos o mundo a nossa volta".

Assim, para nosso trabalho é o passado guardado pelas imagens do litoral fortalezense que nos interessa. Não obstante, a Geografia, ao estudar o pretérito, também está contribuindo à formação do passado. Quando a Geografia está, no presente, disposta a analisar o passado na realidade, "a história reescreve outra vez, de acordo com novas perguntas que se vão formulando em relação às transformações que a sociedade experimenta" (CAPEL, 2006, p. 3). Sobre a importância da preocupação histórica na Geografia, Moraes (2005, p.24) diz que:

Qualquer olhar geográfico já se exercita em uma concepção que sofre determinações históricas, qualquer leitura da paisagem sendo densa de uma temporalidade própria. Se assim é já com os elementos da percepção e da intuição, com muito mais vigor as determinações históricas exercitam-se sobre a elaboração das ideias e a produção dos textos, produtos também de um raciocínio que não foge a tais condicionantes temporais. O conhecimento científico sobre o espaço terrestre sobre seu uso bem exprime essa qualidade.

A Geografia encontra-se presente em todas as épocas históricas e em todas as sociedades que pretendermos estudar. "Pode-se, portanto, dizer que em qualquer período da história e em qualquer agrupamento humano existe uma geografia (material e discursiva) que compõe parte da cultura de cada grupo social e de cada civilização" (MORAES, 2005, p. 24). O próprio Ratzel em sua obra intitulada Antropogeografia (1914), mencionando K. Ritter lembra da relação intrínseca entre Geografia e História:

A ciência geográfica não pode prescindir do elemento histórico, se pretende
ser verdadeiramente um estudo do território e não uma obra abstrata, uma
moldura no interior da qual se observa o vazio, e não a pintura que essa
limita. E, da mesma maneira, a História não pode negligenciar a Geografia,
pois os fatos que ela contempla necessitam de um cenário onde possam
se desenvolver. (...) A História - prossegue afirmando Ratzel nessa mesma
obra - não pode ser compreendida sem a consideração do território
onde se desenvolve, e a Geografia de qualquer parte da Terra não pode
ser representada sem o conhecimento da História, que sobre essa geografia
se imprime deixando suas próprias pegadas (RATZEL, 1914 apud
CARVALHO, 2006, p. 09).

Assim, a proposição vinda da Geografia-Histórica não se refere a uma história estagnada, de eventos consecutivos. Isso se dá porque tampouco a história dá saltos, já que nenhum salto pode acontecer "sem uma causa suficiente, que reside na marcha anterior da evolução social" (PLEKHANOV, 2008, p. 01). Mas sim uma história preocupada com os processos de pensamento que motivaram as ações humanas no passado, "e não simplesmente apreciar fenômenos em seus relacionamentos com o tempo. O conteúdo do campo da História limitase a objetos particulares, isto é, ações humanas que são as consequências do pensamento consciente" (PHILO, 1994, p. 272).

Lewis Munford em sua obra A cidade na História, chama a atenção para a necessidade de se voltar ao passado, ressaltando que se quisermos identificar a cidade, "devemos seguir a trilha para trás, partindo das mais completas estruturas e funções urbanas conhecidas, para os seus componentes originários, por mais remotos que se apresentem no tempo, no espaço e na cultura" (MUNFORD, 1985, p. 81).

Abordagem geo-histórica litorâneas de Fortaleza-CE 


\section{As primeiras fortificações no litoral de Fortaleza}

Sobre as origens de Fortaleza, Jucá (2000, p. 12) conta que: “originalmente, essa capitania foi doada a Antônio Cardoso de Barros, que nem sequer chegou a efetivar a sua posse". Foi somente em 1603, após erradicar, em 1602, o núcleo colonial francês estabelecido em 1590 por Adolf Montbille (o corsário Mambille para os portugueses), e os seus aliados, os Tabajaras da Ibiapaba (atual Viçosa do Ceará), que a expedição do Capitão-mor Pero Coelho de Souza avançou até ao rio Parnaíba, de onde retornou para o rio Ceará.

Em face desse movimento expansionista de conquista, Pero Coelho inicia a onda de ocupações por meio de fortificações ao longo do litoral do que viria a ser Fortaleza, edificando na barra do rio Ceará, a oeste de onde se localizaria mais tarde a futura cidade de Fortaleza, o forte Lusitana de São Thiago (Figura 1).

Figura. 1: "Arx in Ceará". Ribeira do rio Ceará e forte de São Sebastião.

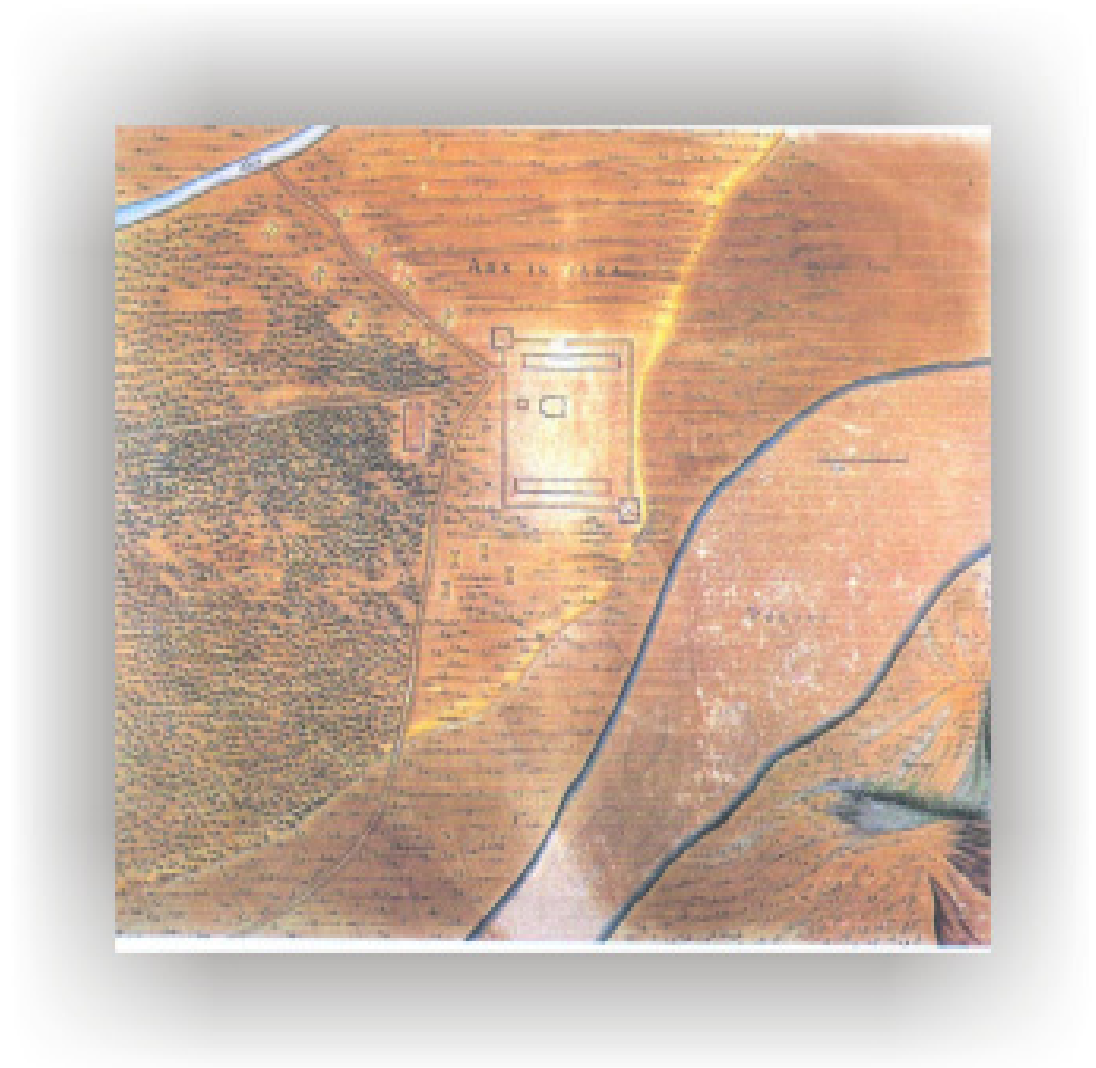

Fonte: Reis, 1994, 31.

Dessa construção, surge ao lado uma povoação conhecida como Nova Lisboa, que posteriormente é batizada pelo capitão-mor de Nova Lusitânia (GARRIDO, 1940, p. 94), sendo o primeiro povoado a se estabelecer no litoral fortalezense pós-descobrimento.

Porém o povoamento dessa área é efêmero, pois houve rapidamente o abandono do forte e da povoação em 1605. Tal fato se deveu a uma série de fatores, tais como a falta de recursos, dos constantes ataques dos indígenas, além das dificuldades de comunicação com a capitania da Paraíba, para onde Pero Coelho havia retornado, deixando a povoação e o fortim sob o comando do capitão Simão Nunes Correia, com uma reduzida guarnição (BARRETO, 1958).

Somente em 1612 é erguida uma nova fortificação, empreendida por Martim Soares Moreno, este coordena a construção do Forte de São Sebastião, no mesmo local do forte onde

Geografia Ensino \& Pesquisa, v. 17, n.3 p. $54-63$, set./dez. 2013

Gonçalves, T.E.; Matos, F.O.

ISSN 2236-4994 57 
fora o de São Thiago. Apesar da precariedade de recursos materiais, esta fortificação teve importante papel no estabelecimento do domínio português na região, repelindo os piratas franceses em 1614. Nesse período, Moreno apaziguou também desacordos entre a população, estimulou a agricultura e a pecuária, assim como repeliu naus neerlandesas por toda a década de 1620 .

Barreto (1958) nos conta a respeito da situação do Forte de São Sebastião durante um momento peculiar da história da ocupação lusitana no nordeste brasileiro, a segunda das invasões holandesas no Brasil, ocorrida entre 1630 e 1654. Nesse período, o autor afirma que foi relatado à Coroa Ibérica que este forte, não condizente com o poderio do Império, sendo apenas de "faxina e terra, e artilhado com duas peças" (BARRETO, 1958, p. 85), deveria ser abandonado, tal como o de São Thiago. Tal situação do Forte resultou na sua invasão em outubro de 1637 (GARRIDO, 1940), empreendida pelas forças holandesas.

Sendo assaltada por uma força de quatrocentos soldados e duzentos indígenas sob o comando do Major Jorge Gartsman, estes se depararam com uma defesa formada por vinte e três homens, sob o comando de Bartolomeu de Brito (GARRIDO, 1940). Barléu (1974, p.31) descreve a situação da ocupação no litoral de Fortaleza no contexto da invasão holandesa:

Os índios moradores do Ceará pediram paz e ofereceram seu auxílio contra os portugueses, rogando ao Conde [Maurício de Nassau] que sujeitasse ao seu poder o forte dali (sic), ocupado pelos lusitanos, protegendo-lhes a gente contra as injúrias e a dominação deles. (...). Arribando Gartsman ao Ceará, informou da sua chegada ao maioral dos brasileiros Algodão, e desembarcada a soldadesca, conduziu-a pelo litoral, vindo-lhe ao encontro os naturais que lhe significavam paz com bandeiras brancas. Depois de falar com o morubixaba, sentindo-se mais animoso com as tropas auxiliares (pois o régulo lhe trouxera de reforço duzentos dos seus), atacou e tomou o forte que era de pedra ensossa (sic). Defendeu-se o inimigo frouxamente, com tiros de peça e de mosquete. Foram poucos os mortos e mais numerosos os prisioneiros, e entre estes os mais graduados da milícia. Lucramos com a vitória três peças e alguns petrechos bélicos. (...) Passando este [forte] para o nosso poder, guarnecemo-lo com um presídio de 40 homens.

As forças holandesas estabelecem seu domínio no Forte de São Sebastião, apesar da infraestrutura que pouco contribuía para os avanços de suas empreitadas. Adriaen van der Dussen no seu Relatório sobre o estado das Capitanias conquistadas no Brasil, de 4 de abril de 1640, confirma:

\footnotetext{
A Capitania do Ceará nunca foi povoada: os portugueses tinham ali somente um pequeno forte, de pouca importância, com muito pouca gente, e do qual nos apoderamos. Atualmente lá está sediada uma guarnição da Companhia, com cerca de 40 homens, mas nada rende à Companhia; contamos com assistência de brasilianos que ali residem, os quais espontaneamente nos vieram em auxílio em três ocasiões, com cerca de 200 homens armados, de cada vez (DUSSEN, 1947, p. 16)
}

Os mesmos índios que apoiaram a invasão são os que provocam a destruição da fortificação, em janeiro de 1644, resultando numa série de ataques próximo ao Porto do Ceará, um trapiche construído pelos holandeses, conforme relata Barléu (1974, p. 304):

Geografia Ensino \& Pesquisa, v. 17, n. 3 p. $54-63$, set./dez 2013

\footnotetext{
Abordagem geo-histórica sobre as primeiras ocupações litorâneas de Fortaleza-CE
}

Depois da expedição do Chile, soube Nassau que estalara no Ceará nova revolta. Bandos de brasileiros, chamados à guerra, tinham tomado ardilosamente o forte ocupado pelos holandeses e o arrasaram, trucidando o governador [do Ceará] Gedeon Morritz, todos os soldados da guarnição e até os trabalhadores estabelecidos não longe dele, nas salinas de Upanema. A mesma sorte estava reservada para o comissário do Maranhão. Ignorando o que ali havia acontecido, arribou aquele lugar infeliz para recensear os soldados e caiu nas mãos dos rebeldes, perecendo com todos os seus de 
morte semelhante. Além disso, como se achasse em reparos no porto do Ceará um dos nossos patachos, desembarcaram num barco o patrão do navio, um capitão, um tenente e alguns soldados rasos, os quais os cearenses, encobrindo o ódio com blandícias, mataram sem eles o esperarem. Evadiram-se três marinheiros que se haviam escondido no mato e viram o forte derribado e seus entulhos.

Os indígenas entregam a fortificação a Antônio Teixeira de Melo, a quem mandam chamar do Maranhão (SOUZA, 1885). Abandonado, seus canhões e telhas foram aproveitados mais tarde para a construção do Forte Schoonenborch, em abril de 1649 (GARRIDO, 1940).

Esse novo forte surgiu dado o abandono do Fortim de São Sebastião, e com nova posição defensiva na costa do Ceará erguida no contexto da segunda invasão holandesa do Brasil, transcorrida entre 1630 e 1654 . No espaço que corresponde a atual cidade de Fortaleza, os holandeses direcionavam-se a serra de Maranguape na busca por metais preciosos.

A expedição de Matias Beck buscava essencialmente as minas de prata ou de ouro (nunca encontradas), para confecção no Ceará de joias e adereços. Tanto isso é verdade que ele trouxe consigo os melhores ourives, entre eles Jonas Laurentes, de Ausburg, prateiros e mineiros, e ferramentas especiais para a extração de minérios (ESPÍNOLA, 2007).

Navegadores de formação, esses desbravadores mantinham grandes relações com suas embarcações, atracadas nas proximidades do Mucuripe (CASTRO, 1977). A transferência da ocupação da foz do rio Ceará para a do riacho Pajeú vem possuir também este outro viés, a busca de uma maior proximidade da zona exploratória com o ancoradouro ${ }^{1}$.

Com traçado de autoria do Engenheiro holandês Ricardo Caar, o forte foi construído pelas tropas de Mathias Beck que limparam o terreno, erguendo uma cerca de pau-a-pique, faltando instalar o portão e concluir duas baterias (GARRIDO, 1940, p.42). Inicialmente de madeira (estacas de carnaúba) e terra, sua planta apresentava a forma de um polígono pentagonal, cercada com parapeito e paliçada (BARRET'TO, 1958, p.89), aproveitando material e artilharia do antigo Fortim de São Sebastião (GARRIDO, 1940, p.42).

Sobre o monte Marajaitiba, que significa lugar de muitas palmeiras, se instalou a nova fortificação, batizada como Forte Schoonemborch, em homenagem ao Governador holandês de Pernambuco, ficando guarnecido por quarenta homens e artilhado com onze peças de ferro (BARRETTTO, 1958, p.89). De pequenas dimensões, Mathias Beck determinou posteriormente a sua ampliação e reforço das obras de defesa, de acordo com a planta do mesmo Engenheiro Caar, o que foi iniciado a 19 de agosto de 1649 (BARRET'TO, 1958, p.89).

Desse período existe um croqui de 1649 com a localização do respectivo forte (Figura 2). Esse desenho dá o alinhamento da costa desde o cabo Mocuripe ${ }^{2}$ (também conhecido como Mucuriba e Mucurive, posteriormente Mucuripe) até a barra do rio Itarema, que significa "local da casa do índio chefe Carajá" (BRÍGIDO, 1912, p. 84).

Em 1654 atracou na enseada do Mocuripe uma caravela portuguesa com sete capitães e 150 soldados fortemente armados, sob o comando de Álvaro Azevedo Barreto, para render os holandeses. Beck, negociando uma transferência pacífica, entrega as chaves do Schonenborch aos lusitanos, que passou a se chamar Fortalez̧a de Nossa Senhora da Assunção.

\section{Forte Nossa Senhora da Assunção}

No contexto da retomada portuguesa é efetivado a transferência do emergente povoado - da foz do rio Ceará para o entorno do forte de Schonenborch, renomeado pelos portugueses de forte de Nossa Senhora da Assunção. Sobre esse processo, relata Oliveira (1888, p. 62):

1706. 24 de Fevereiro. O Capitão-mór do Ceará, Gabriel da Silva Lagos propôz à Câmara da Villa de São José de Riba-mar a mudança da mesma
1- Num olhar rápido a Barra do Ceará, subindo pelo vale do rio, seria o melhor ponto para o alcance do sopé da serra, porém como nos lembra Castro (1977) o problema de assoreamento desse rio não é apenas uma situação da atualidade, encontrando-se já na época da invasão holandesa completamente assoreado, impraticável para qualquer desembarque.

2- Em Iracema (2000) José de Alencar aproveita o romance para buscar uma explicaçã̃o do termo Mocuripe, num diálogo entre Tupi e Martim:"Por que chamas tu Mocoripe, ao grande morro das areias? - O pescador da praia, que vai na jangada, lá de onde voa a ati, fica triste, longe da terra e de sua cabana, em que dormem os filhos de seu sangue. Quando ele torna e seus olhos primeiro avistam o morro das areias o prazer volta a seu coração. Por isso ele diz que o morro das areias da alegria" (ALENCAR, 2000, p. 56). Mais detalhadamente, Mocoripe origina-se de Corib - alegrar, e mo, partícula ou abreviatura do verbo monhang fazer (FALCÃO, 2005)

Geografia Ensino \& Pesquisa, v. 17, n. 3 p. 54 - 63, set./dez. 2013

Gonçalves, T.E.; Matos, F.O.

ISSN 2236-4994 59 
3- Sobre essa questão Castro (1977, p.23) afirma que se os portugueses, no caso fortalezense, aproveitaram a estrutura da fortificação holandesa, fizeram-no porque, independente dos fatores evidentes que eliminavam a Barra e o Mucuripe, sua localização por coincidência atendia à concepção particular de fixação que defendiam, posto que nenhuma outra dentro da área pesquisada, se ajustava tanto às suas aspirações. Mantinham uma herança latina, pois "Roma construíra muitas vezes cidades sobre destroços das povoações bárbaras conquistadas, desde que estas contivessem os requisitos de localização a que obedecia. A nova cidade renascia, ou nascia, romana, portanto, traduzindo a marca inconfundível de seus fundadores. Assim, também a cidade portuguesa, tantas vezes erguida sobre ruínas do alcácer mouro" (CASTRO, 1977, p. 23).

Geografia Ensino \& Pesquisa, v. 17, n. 3 p. 54 - 63, set./dez 2013

\footnotetext{
Abordagem geo-histórica sobre as primeiras ocupações litorâneas de Fortaleza-CE
}

villa, da barra do rio Ceará, onde estava situada, para a Fortaleza de Nossa Senhora da Assumpção. (...) No dia 26 o Senado da mesma Câmara se reúne a pedido do povo, e delibera a mudança.

Essa política de fortificação foi à proposta inicial de colonização portuguesa no território brasileiro, ocupando a partir do litoral da foz do rio Amazonas ao rio da Prata, tendo como ponto de partida as feitorias litorâneas. José Liberal de Castro (1977) traz um texto esclarecedor sobre o padrão da colonização portuguesa no Brasil e a discussão sobre quem tomara o início de Fortaleza, quer seja portuguesa ou holandesa ${ }^{3}$.

A fabricação de representações gráficas do espaço que viria a ser Fortaleza é resultado da preocupação em dotar a zona costeira de edificações para a proteção do território recém descoberto. Assim como a Planta do Forte de Schonemborch, é criada ao longo do século XVII uma série de desenhos cartográficos a fim de delinear a zona costeira a ser fortificada. Sem haver uma preocupação rígida com a escala ou uma representação mais detalhada, esses desenhos surgem com o objetivo de levar à Europa a descrição do território conquistado, bem como o estabelecimento de rotas marítimas, visando a interligação dos novos povoados à metrópole.

O detalhamento do perfil litorâneo nas plantas do século XVI, além de visar contribuir para a descrição dessas novas rotas, objetivava também colaborar com as primeiras tentativas portuárias, na busca de estabelecer um lugar para a construção de uma zona de atracação de embarcações. Com o crescimento da vila ao redor do forte Schoonemborch, e sua efetivação no contexto sócio-político do Siara, percebemos a opção de situar o primeiro trapiche próximo a essa aglomeração.

Figura 2 : "Planta do Forte de Schoonemborch" e o perfil da zona costeira no século XVII.

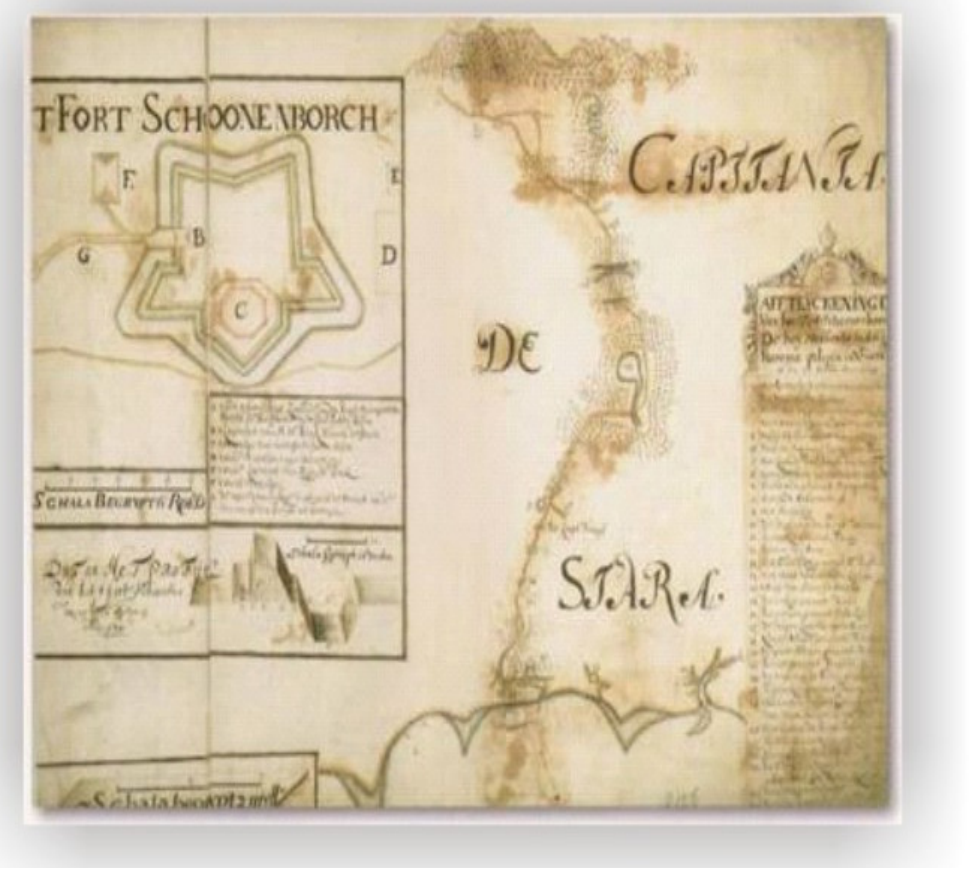

Fonte: Castro, 1981, p. 08

Sobre a ocupação costeira em Fortaleza nos anos iniciais após o descobrimento temos a obra máxima da literatura cearense, o romance indianista Iracema. Escrito por José Martiniano de Alencar em 1865, o livro retrata o enlaço entre a índia Iracema, a "virgem formosa do sertão" (ALENCAR, 2000, p. 44), e Martim Soares Moreno, o "guerreiro branco vindo do 
mar" (ALENCAR, 2000, p. 54).

A presença do litoral e sertão é predominante na obra de José de Alencar, servindo como fonte para o conhecimento da forma de ocupação desses espaços à luz das primeiras investidas no então Ceará. Silva (2006) dá sua opinião sobre o ambiente litorâneo presente em Iracema, ao afirmar que nas páginas iniciais do romance, o mar vai adquirindo feições de lugar privilegiado, trazendo uma perspectiva em que a linha de visada é fixada a partir do mar. No período de fortificação do litoral a figura do ambiente marítimo expressa tal misticismo que é também do mar que Alencar aponta o lugar de nascimento da virgem do Sertão. "Além, muito além daquela serra, que ainda azula no horizonte nasceu Iracema” (ALENCAR, 2000, p. 16).

Recordando o misticismo acerca da visão do ambiente costeiro pelos lusitanos, não é estranho notar que a costa fortalezense, apesar de tomada por um lastro de fortificações, passará um longo período sendo ignorada pelo governo português - quer seja exploratório (depois do fracasso das expedições de Beck) ou de ocupação -, permanecendo inóspita e povoada por índios não amistosos. O mar, ponto de início da colonização cearense, vem se configurar nos primórdios do crescimento da cidade, como um local ad fora de Fortaleza, apesar de toda a dinâmica mobilizada pelas fortificações. A faixa praiana em todo o Ceará passaria a ser considerada nesse período como "terra de ninguém, ora pertencendo ao chamado estado do Maranhão ora ao estado do Brasil" (CASTRO, 1977, p. 24).

\section{Considerações Finais}

Até 1799 - ano do desmembramento do Ceará da Província de Pernambuco - Fortaleza era uma vila sem importância econômica. Dentre os poucos povoados àquela época, destacavamse naquela época as vilas de Aracati, Icó, Sobral, Crato, Camocim, Acaraú e Quixeramobim. Isso se dava pelo motivo da principal atividade econômica da província ser a pecuária, com a exportação de carne, couro e animais de tração para a Zona da Mata nordestina.

Perdendo sua função enquanto "salvaguarda" das terras portuguesas, a fortaleza da capital passa a desempenhar um papel mais ligado ao ordenamento e controle do espaço da vila. No entanto, dado o fato de Fortaleza permanecer distante da atividade criatória desenvolvida no interior da Capitania, seu povoado vem se estruturar-se de modo tímido, sob a ótica do primeiro Governador do Ceará, Bernardo Manuel de Vasconcelos como "um montão de areia... apresentando do lado pequenas casas térreas... incluindo a muito velha e arruinada casa dos Governadores" (JUCÁ, 2000, p. 28).

Analisando as relações estabelecidas na formação de Fortaleza e a tomada dos primeiros contatos tidos com seu ambiente costeiro na formação do referido município, percebe-se o intricado relacionamento formado entre o homem e o mar. Tal relação perpassa até os anos iniciais do século XX como cerne da complexa formação urbana de um município litorâneo, mas que ignora sua zona litorânea como zona de expansão ao longo de quase toda sua história.

\section{Referências}

ALENCAR, J. Iracema: lenda do Ceará. São Paulo: Ática, 2000.

BARLÉU, G. História dos feitos recentemente praticados durante oito anos no Brasil. Belo Horizonte: Itatiaia, 1974.

Geografia Ensino \& Pesquisa, v. 17, n. 3 p. $54-63$, set./dez. 2013

BARRETTO, A. Fortificações no Brasil (Resumo Histórico). Rio de Janeiro: Biblioteca do Exército Editora, 1958.

Gonçalves, T.E.; Matos, F.O. 
CAPEL, H. El VIII Coloquio Internacional de Geocrítica: una geografía histórica para construir el futuro. Scripta Nova. Revista electrónica de geografía y ciencias sociales. Barcelona: Universidad de Barcelona, 1 de agosto de 2006, vol. X, núm. 218. Disponível em: http://www.ub.es/geocrit/sn/sn-218-001.htm. Acessado em 5 de janeiro de 2008.

CARVALHO, M. B. Geografia e história, tradição e modernidade: fundamentos da geopolítica contemporânea. Scripta Nova. Revista electrónica de geografía y ciencias sociales. Barcelona: Universidad de Barcelona, 1 de agosto de 2006, vol. X, núm. 218 (23). Disponível em: http://www.ub.es/geocrit/sn/sn-218-23.htm. Acessado em 8 de janeiro de 2008.

CASTRO, J. L. Fatores de localização e de expansão da cidade de Fortaleza. Fortaleza: Imprensa Universitária, 1977.

CASTRO, J. L. Parque Pajeú. Fortaleza: Sumov, 1981.

CORIOLANO, L. N. Do local ao global: o turismo litorâneo cearense. Campinas: Papirus, 1998.

DIÓGENES, B. H. N. Aldeota: um bairro em mutação. Trabalho de Conclusão de Curso (Aperfeiçoamento em Arquitetura e Instrumentação Crítica) - Universidade Federal do Ceará, Fortaleza, 1984.

DUSSEN, A. V. D. Relatório sôbre as capitanias conquistadas no Brasil pelos holandeses (1639): suas condições econômicas e sociais. Rio de Janeiro: Ind. Graf. J. Lucena, 1947.

ESPÍNOLA, R. Caravelas, jangadas e navios: uma história portuária. Fortaleza: OMNI, 2007.

FACÃO, M. F. P. Dicionário toponímico, histórico e geográfico do Nordeste. Fortaleza: Artlaser, 2005.

GARRIDO, C. M. Fortificações do Brasil. Separata do vol. III dos subsídios para a história marítima do Brasil. Rio de Janeiro: Imprensa Naval, 1940.

GIOVANINI, R. R. Regiões em movimento: um olhar sobre a Geografia-Histórica do sul de Minas e da Zona da Mata Mineira (1808-1897). 2006. Dissertação (Mestrado em História) - Universidade Federal de Minas Gerais, Belo Horizonte, 2006.

JUCÁ, G. N. M. Verso e reverso do perfil urbano de Fortaleza, 1945-1960. São Paulo: Annablume, 2000.

LOWENTHAL, D. Como conhecemos o passado. Revista Projeto História: trabalhos da memória. São Paulo, v.17, p. 63-201, 1998.

MORAES, A. C. R. Território e história no Brasil. São Paulo: Hucitec/Annablume, 2005.

Geografia Ensino \& Pesquisa, v. 17, n. 3 p. $54-63$, set./dez 2013

Abordagem geo-histórica sobre as primeiras ocupações litorâneas de Fortaleza-CE
MUNFORD, L.A. A cidade na história. São Paulo: Edusp, 1985.

REIS, N. G. Algumas experiências urbanísticas do início da República (1890/1920). Cadernos de Pesquisa do Laboratório de Estudos sobre Urbanização, Arquitetura e Preservação. São Paulo, v. 1, p. 33-52, 1994.

OLIVEIRA, J. B. O resumo chronológico para a história do Ceará. Revista do Instituto do Ceará. Fortaleza, Ceará, v. 02, p. 25-79, 1888. 
PLEKHANOV, G.V. Os “saltos" da natureza e na história. Disponível em: http://marx. org/portugues/plekhanov/misc/saltos-natu-historia.htm. Acessado em 05 de janeiro de 2008.

PHILO, C. História, Geografia, e o mistério ainda maior da geografia histórica. In: GREGORY, D.; MARTIN, R.; SMITH,G. (org.) Geografia Humana: sociedade, espaço e ciência social. Rio de Janeiro: Jorge Zahar, 1994. p. 269-98.

SILVA, J. B. Os lugares de Iracema. In: GOVERNO DO ESTADO CEARÁ. Iracemas: imagens de uma lenda. Fortaleza, Barbarela B. Comunicação e Marketing, 2006. p. 59-71.

SOUZA, A. F. Fortificações no Brazil. RIHGB. Rio de Janeiro, p. 5-140. Rio de Janeiro [s.e.], 1885.

\section{Correspondência:}

\section{Tiago Estevam Gonçalves}

E-mail: tiagoestevam@ifce.edu.br

Recebido em 12 de abril de 2013.

Parecer emitido em 15 de maio de 2013

Revisado pelo autor em 09 de junho de 2013.

Aceito para publicação em 11 de julho de 2013 